\title{
Evaluation of Spring Barley Performance by Biplot Analysis
}

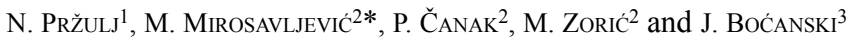 \\ ${ }^{1}$ Faculty of Agriculture, University of Banja Luka, Bulevar vojvode Petra Bojovića 1A, 78000 Banja Luka, \\ Bosnia and Herzegovina \\ ${ }^{2}$ Institute of Field and Vegetable Crops, Maksima Gorkog 30, 21000 Novi Sad, Serbia \\ ${ }^{3}$ Faculty of Agriculture, University of Novi Sad, D. Obradovića 8, 21000 Novi Sad, Serbia
}

(Received 6 November 2014; Accepted 28 January 2015)

\begin{abstract}
Unpredictable environmental conditions lead to occurrence of large genotype by environment $(\mathrm{G} \times \mathrm{E})$ interaction. It reduces the correlation between genotypic and phenotypic values and complicates selection of superior genotypes. The objective of this study was to estimate genotype by year $(\mathrm{G} \times \mathrm{Y})$ interaction using AMMI model, to identify spring barley genotypes with stable and high yield performance and to observe association of different meteorological variables with tested growing seasons. The trials with 15 spring barley genotypes were conducted during seven years (1999-2005) at the location of Rimski Šančevi. The results showed that the influence of year $(Y)$, genotype $(G)$ and $G \times Y$ interaction on barley grain yield were significant $(\mathrm{p}<0.01)$. Meteorological variables varied significantly from year to year and $\mathrm{Y}$ explained the highest percent of treatment variation $(81 \%)$. The first three IPCA were significant and explained $83 \%$ of interaction variation. According to this study, it could be concluded that AMMI analysis provided an enhanced understanding of $\mathrm{G} \times \mathrm{Y}$ interaction in barley multi-years trials. Among the tested genotypes, LAV and NS 477 could be separated as highest yielding genotypes, however LAV could be recommended for further breeding program and large-scale production due to its stable and high yielding performance. It also provided better insight in specific association between spring barley grain yield and meteorological variables.
\end{abstract}

Keywords: AMMI analysis, genotype by year interaction, grain yield, Hordeum vulgare L., meteorological variables

\section{Introduction}

Barley is one of the most important small-grain cereal crops in the world. Compared to other cereals, it is ranked as fourth in the world production, behind maize, rice and wheat (FAOSTAT 2012). Barley is a cereal with wide range production area in the world, grown in different regions and climate conditions, from the desert climate in Africa, the Middle East and China to the northern regions of Asia, Europe and North America, and from sea level to over $4000 \mathrm{~m}$ on the Tibetan Plateau. Although it is less susceptible to influence of drought stress in comparison to other cereals (such as rye and wheat), abiotic stress is a major limiting factor for crop production (Ullrich 2011).

\footnotetext{
*Corresponding author; E-mail: milan.mirosavljevic@nsseme.com
} 
Different ecological stresses as well as their combinations have significant influence on plant physiology and growth (Shah and Paulsen 2003), and often lead to significant grain loss. Knowledge about the influence of environmental factors on growth and development phases of certain crops could improve selection of stable genotypes and reduce possibilities of yield decrease in various environments. The Pannonian region, which includes Hungary and parts of Serbia and Romania, is characterized by high year-to-year climate variability and there are chances of further increase in the occurrence of undesirable seasons for spring barley production due to climate change (Olesen et al. 2011). These undesirable years are characterized by increased temperature and lack of rainfall during the period of ear development, pollination and grain filling period (Pržulj and Momčilović 2012). Heat and drought stress are significant reasons why production of spring barley in this region is more insecure than winter barley production (Metzger et al. 2005).

Inconsistent genotypic responses to different environmental conditions (precipitation, temperature, disease attack and soil type or fertility level) from location to location and year to year are result of genotype $\times$ environment $(G \times E)$ interactions. The $G \times E$ interaction, defined as changes in cultivar rank in different environments, is important because it reduces correlation between genotypic and phenotypic values and complicates selection of superior genotypes. It also complicates prediction of genotype reaction to different combination of climatic conditions (Ceccarelli 1989). Therefore, plant breeders have to properly evaluate and understand $\mathrm{G} \times \mathrm{E}$ interaction and also to examine the response of newly developed genotypes to different climatic variables.

The study of genotype-location $(\mathrm{G} \times \mathrm{L})$ interaction is of essential interest for breeding programmes since it may lead to the subdivision of a target region into different sub-regions in order to exploit specific adaptation effects (Annichiarico 1997). Previous studies were usually based on interaction of genotype by location and/or a combination of location-year (Mitrović et al. 2012), while little or no attention is focused on the genotype $\times$ year interaction. Growing conditions are also variable from one growing season to another on one location, as well as from one location to another in a single growing season (Kilic et al. 2009; Mladenov et al. 2012). Investigation of genotype by year interaction could improve the selection of genotypes with higher yield stability across environments.

Nonparametric, regression and multivariate approaches have been used to understand the $\mathrm{G} \times \mathrm{E}$ interaction pattern (Zobel et al. 1988). Among multivariate analysis models, the additive main effects and multiplicative interaction (AMMI) biplot and the genotype main effect and genotype $\times$ environment interaction (GGE) biplot have been frequently used to visualize $G \times E$ interaction. The main differences of the two methods, AMMI analysis is referred to double-centered principal component analysis (PCA), whereas GGE biplot analysis is based on environment-centered PCA (Rao et al. 2011). The AMMI model incorporates analysis of variance (ANOVA) and PCA in a single statistical model (Gauch and Zobel 1996). In AMMI models, using ANOVA additive effect is separated from interaction, and then PCA is applied to analyze interaction effect (Kaya et al. 2002). The biplot graphic presentation shows both main and interaction effects for genotypes and environments simultaneously and provides a more in-depth analysis of $\mathrm{G} \times \mathrm{E}$ interaction (Zobel et al. 1988). 
In this study, the main objective was to estimate $\mathrm{G} \times \mathrm{Y}$ interaction using AMMI method and identify spring barley genotypes with stable response and high yield performance across seven growing seasons. Furthermore, the objective was to observe association of spring barley grain yield with different meteorological variables throughout the years, which could provide better understanding of barley performance.

\section{Materials and Methods}

\section{Data}

The plant material consisted of 15 spring barley genotypes developed at the Institute of Field and Vegetable Crops Novi Sad, Serbia. The trial was conducted during seven growing seasons (1999-2005), arranged in a randomized complete block design with three replications at location Rimski Šančevi $\left(45^{\circ} 20^{\prime} \mathrm{N}\right.$ and $\left.19^{\circ} 51^{\prime} \mathrm{E}\right)$, Serbia. The experimental plot was $5 \mathrm{~m}^{2}$, with plant density of 500 germinated kernels per $\mathrm{m}^{2}$. Standard agricultural practice was conducted in all investigated seasons. All trials were fertilized in doses consistent with good agricultural practice, based on soil agrochemical analysis. Barley grain yield $\left(\mathrm{t} \mathrm{ha}^{-1}\right)$ was adjusted to the $14 \%$ moisture.

\section{Meteorological variables}

In order to examine association between environment and meteorological records, minimum, maximum and average daily temperature and precipitation during three growth phases were recorded for each growing year. Meteorological records were obtained from the official meteorological station of Hydrometeorological Service of the Republic of Serbia, which is located near the experimental field. From these data 15 meteorological variables was constructed: precipitation accumulated during the emergence-heading period (Pre.EH), the heading-maturity period (Pre.HM) and the interval seven days beforeseven days after heading (Pre.H); daily minimum temperature averaged across the emergence-heading period (Tmin.EH), the heading-maturity period (Tmin.HM) and the interval seven days before-seven days after heading (Tmin.H); daily maximum temperature averaged across the emergence-heading period (Tmax.EH), the heading-maturity period (Tmax.HM) and during the interval seven days before-seven days after heading (Tmax.H); daily medium temperature averaged across the emergence-heading period (Tmed.EH), the heading-maturity period (Tmed.HM) and the interval seven days before-seven days after heading (Tmed.H); dTb0.EH, number of days with minimum temperature below $0{ }^{\circ} \mathrm{C}$ across the emergence-heading period; dTo25.H number of days with maximum temperature over $25^{\circ} \mathrm{C}$ during the interval seven days before-seven days after heading; dTo30.HM, number of days with maximum temperature over $30^{\circ} \mathrm{C}$ across the headingmaturity period; as previously proposed by Ceretta and van Eeuwijk (2008) and Romagosa et al. (2009). PCA analysis was performed on the set of the meteorological indices and grain yield and biplot of the first two PCA axes was constructed to visualize association between environments, grain yield and meteorological variables. 


\section{Data analysis}

The AMMI model was used to assess the $\mathrm{G} \times \mathrm{E}$ interaction, and it can be represented by the following formula (Gauch and Zobel 1996):

$$
Y_{g e r}=\mu+\alpha_{g}+\beta_{e}+\sum_{n} \lambda_{n} \gamma_{g n} \delta_{e n}+\rho_{g e}+\varepsilon_{g e r}
$$

where $Y_{g e r}$ is the yield for the genotype $g$ in the environment $e$ the replication $r$. The additive parameters are: $\mu$ - the grand mean, $\alpha_{g}-$ a/the genotypic mean deviation from the grand mean, $\beta_{e}$ - the environmental mean deviation. The multiplicative parameters are: $\lambda_{n}$ - a singular value for $n$ interaction principal component axis $n, \gamma_{g n}$ - the genotypic eigenvector for IPCA axis $n, \delta_{e n}$ - the eigenvector of the environment for IPCA axis $n$, $\rho_{g e}-$ a residue when not all PCA axis are included and $\varepsilon_{g e r}-$ the error.

Software StatSoft, Inc. (2011), STATISTICA (data analysis software system, version 10 (www.statsoft.com) was used for two-way ANOVA and means were compared using Tukey's test. AMMI analyses were performed in Excel Biplot Macros (Lipkovich and Smith 2002).

\section{Results}

\section{Correlation between years and meteorological variables}

The PCA analysis of the meteorological data and grain yield in seven years is presented in a biplot with first two principal components (Fig. 1). The meteorological variables, years and grain yield vector are placed on biplot according to their PCA scores. In GT biplot, correlation coefficient between any two traits is approximated by cosine of the angle between their vectors, so that $r=\cos 180^{\circ}=-1, \cos 0^{\circ}=1$, and $\cos 90^{\circ}=0$ (Yan and Rajcan 2002). PCA1 accounted 50.07\%, while PCA2 accounted a $26.88 \%$ of total variation.

Year 1999 was positioned near the coordinate beginning, which indicates average environmental conditions in that year. High temperatures at heading period, low temperatures at emergence-heading period and high number of days with extreme temperatures at all phases were recorded in year 2000. Year 2001 was characterized by high precipitation at all growing phases, low number of days with extreme temperatures and lower temperatures at heading and heading-maturity period. Average environmental conditions were recorded in year 2002. The highest minimum and maximum temperatures at emergenceheading and heading-maturity periods, the lowest precipitation and high number of days with temperatures over $30^{\circ} \mathrm{C}$ at heading-maturity period were observed in year 2003 . This year was also characterized with the lowest grain yield. The weather conditions in year 2004 were similar to year 2001, with less precipitation and slightly higher temperature at emergence-heading and heading-maturity periods. Year 2005 was placed on biplot near 1999 and 2002, indicating similar meteorological conditions. Precipitation levels during all three growing phases were highly associated. Also, Tmed, dTo25 and Tmax at 


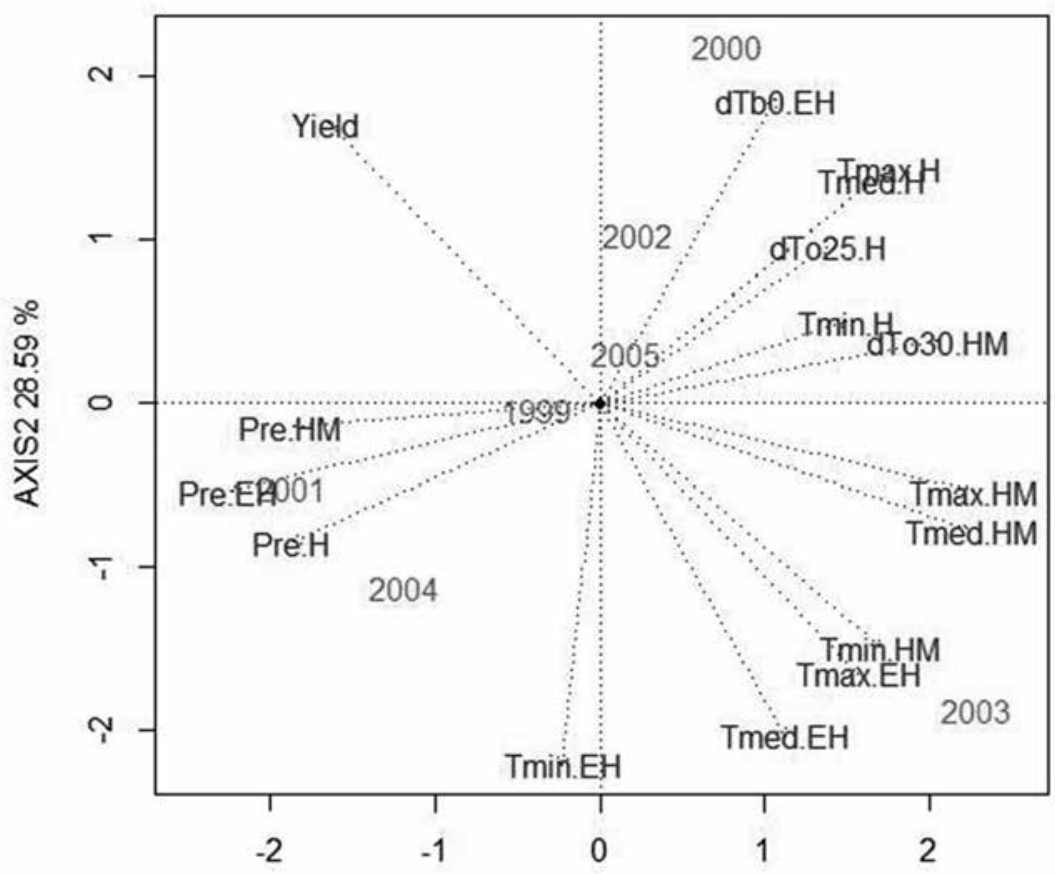

AXIS1 $49.36 \%$

Figure 1. Biplot presentation of barley grain yield, 15 environmental variables across seven years (1999-2005)

heading period were highly correlated. Temperatures below zero at EH did not affect grain yield, as indicated by near perpendicular vectors. Similar situation was with grain yield and temperature variables calculated at H. Only Tmin.H had weak negative association with grain yield. All temperatures variables at EH and HM, except previously mentioned dTbO.EH, were negatively associated with grain yield. Precipitation at headingmaturity period had higher association with grain yield than precipitation at other growing phases.

\section{AMMI model}

The ANOVA showed that genotype $(\mathrm{G})$, year $(\mathrm{Y})$ and $\mathrm{G} \times \mathrm{Y}$ had significant effect $(p<0.01)$ on barley grain yield (Table 1). Difference between G explained 6.79\% of treatment variation, while effect of $\mathrm{G} \times \mathrm{Y}$ explained $12.25 \%$. Effect of $\mathrm{Y}$ on barley yield was higher than the influence of $\mathrm{G}$ and $\mathrm{G} \times \mathrm{Y}$, and the proportion of sum of squares due to differences among $\mathrm{Y}$ was $80.97 \%$ of treatments variation. These data indicate that climatic conditions were very diverse between growing seasons. The presence of genotype by year interaction indicates that genotypes tended to rank differently in grain yield at 
Table 1. The additive main effects and multiplicative interactions analysis of variance for barley grain yield

\begin{tabular}{|l|c|c|c|c|c|}
\hline \multicolumn{1}{|c|}{ Source } & df & SS & MS & F & SS (\%) \\
\hline Genotype & 14 & 34.8 & 2.49 & 8.58 & $6.79^{* *}$ \\
\hline Year & 6 & 415.2 & 69.20 & 176.36 & $80.97^{* *}$ \\
\hline Interaction & 84 & 62.8 & 0.75 & 2.58 & $12.25^{* *}$ \\
\hline IPCA1 & 19 & 27.5 & 1.445 & 4.98 & $43.79^{* *}$ \\
\hline IPCA2 & 17 & 14.6 & 0.86 & 2.96 & $23.25^{* *}$ \\
\hline IPCA3 & 15 & 10.2 & 0.68 & 2.34 & $16.24^{* *}$ \\
\hline Residuals & 33 & 10.6 & 0.91 & 3.14 & - \\
\hline Block & 14 & 5.5 & 0.39 & 1.35 & - \\
\hline Error & 196 & 56.8 & 0.29 & - & - \\
\hline
\end{tabular}

**Significance at 0.01 probability level.

Table 2. Average grain yields $\left(\mathrm{t} \mathrm{ha}^{-1}\right)$ of 15 spring barley varieties over seven years

\begin{tabular}{|c|c|c|c|c|c|c|c|c|}
\hline \multirow{2}{*}{ Genotype } & \multicolumn{9}{|c|}{ Growing seasons } \\
\cline { 2 - 9 } & 1999 & 2000 & 2001 & 2002 & 2003 & 2004 & 2005 & Average \\
\hline JELEN & 7.02 & 7.00 & 7.13 & 6.97 & 3.45 & 5.33 & 5.72 & $6.09^{\mathrm{abc}}$ \\
\hline LAV & 6.79 & 7.57 & 8.26 & 6.97 & 3.35 & 6.27 & 7.37 & $6.65^{\mathrm{a}}$ \\
\hline NS294 & 5.54 & 6.83 & 4.61 & 5.89 & 3.21 & 4.69 & 7.23 & $5.43^{\mathrm{d}}$ \\
\hline NS447 & 7.17 & 7.50 & 8.08 & 6.46 & 3.32 & 5.95 & 6.97 & $6.49^{\mathrm{a}}$ \\
\hline NS450 & 5.79 & 6.82 & 5.85 & 6.18 & 3.16 & 5.11 & 6.07 & $5.57^{\mathrm{cd}}$ \\
\hline NS454 & 7.39 & 6.82 & 6.81 & 6.28 & 3.51 & 5.95 & 6.37 & $6.16^{\mathrm{ab}}$ \\
\hline NS456 & 7.61 & 6.83 & 7.37 & 6.42 & 4.06 & 6.50 & 6.35 & $6.45^{\mathrm{ab}}$ \\
\hline NS460 & 6.51 & 7.25 & 7.13 & 5.44 & 3.84 & 6.31 & 6.59 & $6.15^{\mathrm{ab}}$ \\
\hline NS462 & 6.34 & 6.62 & 7.70 & 5.73 & 3.44 & 5.63 & 5.71 & $5.88^{\mathrm{bcd}}$ \\
\hline NS466 & 7.09 & 6.58 & 6.29 & 5.83 & 3.65 & 5.77 & 5.93 & $5.88^{\mathrm{bcd}}$ \\
\hline NS470 & 7.83 & 6.29 & 6.91 & 6.49 & 3.52 & 6.20 & 6.80 & $6.29^{\mathrm{ab}}$ \\
\hline NS476 & 7.04 & 7.51 & 7.41 & 6.48 & 3.52 & 5.31 & 6.73 & $6.28^{\mathrm{ab}}$ \\
\hline PEK & 6.56 & 6.80 & 6.88 & 6.60 & 3.61 & 6.00 & 7.23 & $6.24^{\mathrm{ab}}$ \\
\hline UROS & 6.92 & 7.26 & 7.07 & 6.88 & 3.40 & 6.66 & 6.55 & $6.39^{\mathrm{ab}}$ \\
\hline VIKTOR & 7.73 & 7.18 & 7.25 & 7.41 & 3.50 & 6.12 & 5.95 & $6.45^{\mathrm{ab}}$ \\
\hline Average & $6.89^{\mathrm{a}}$ & $6.99^{\mathrm{a}}$ & $6.98^{\mathrm{a}}$ & $6.40^{\mathrm{b}}$ & $3.50^{\mathrm{d}}$ & $5.85^{\mathrm{c}}$ & $6.50^{\mathrm{b}}$ & - \\
\hline
\end{tabular}

Different letters indicate significant difference at $P<0.05$ level. 
different years. The results of AMMI analysis revealed that the first IPCA covered $43.79 \%$ of $\mathrm{G} \times \mathrm{Y}$ sum of squares, while the second and third IPCA explained further $23.25 \%$ and $16.24 \%$ interaction sum of squares (Table 1). The first three IPCA cumulatively contributed to a total $83.3 \%$ interaction, with $60 \%$ for corresponding degrees of freedom. In addition, sum of squares of IPCA1, IPCA2 and IPCA3 was higher than a sum of squares of G.

Genotypes grain yield varied from to 3.16 to $8.26 \mathrm{t} \mathrm{ha}^{-1}$ through seasons (Table 2). Genotype LAV, followed by NS447, were the highest yielding genotypes, with an average yield of $6.5 \mathrm{t} \mathrm{ha}^{-1}$. Genotype NS294 had the lowest average yield. Average yield per year varied between $3.50 \mathrm{t} \mathrm{ha}^{-1}$ in 2003 and $6.99 \mathrm{t} \mathrm{ha}^{-1}$ in 2000 .

In AMMI1 (Fig. 2), abscissa represents the main effects ( $\mathrm{G}$ and $\mathrm{Y})$ and ordinate represents the effects of the interaction (IPCA1). The values plotted closer to the $x$-axis contribute less to the interaction than values placed further away. Therefore, genotypes with small IPCA1 values have higher stability. AMMI1 biplot showed that the majority of genotypes was located around average yield $\left(6.16 \mathrm{tha}^{-1}\right)$ and had small IPCA1 values, except NS294 which was located furthest from $x$ axis.

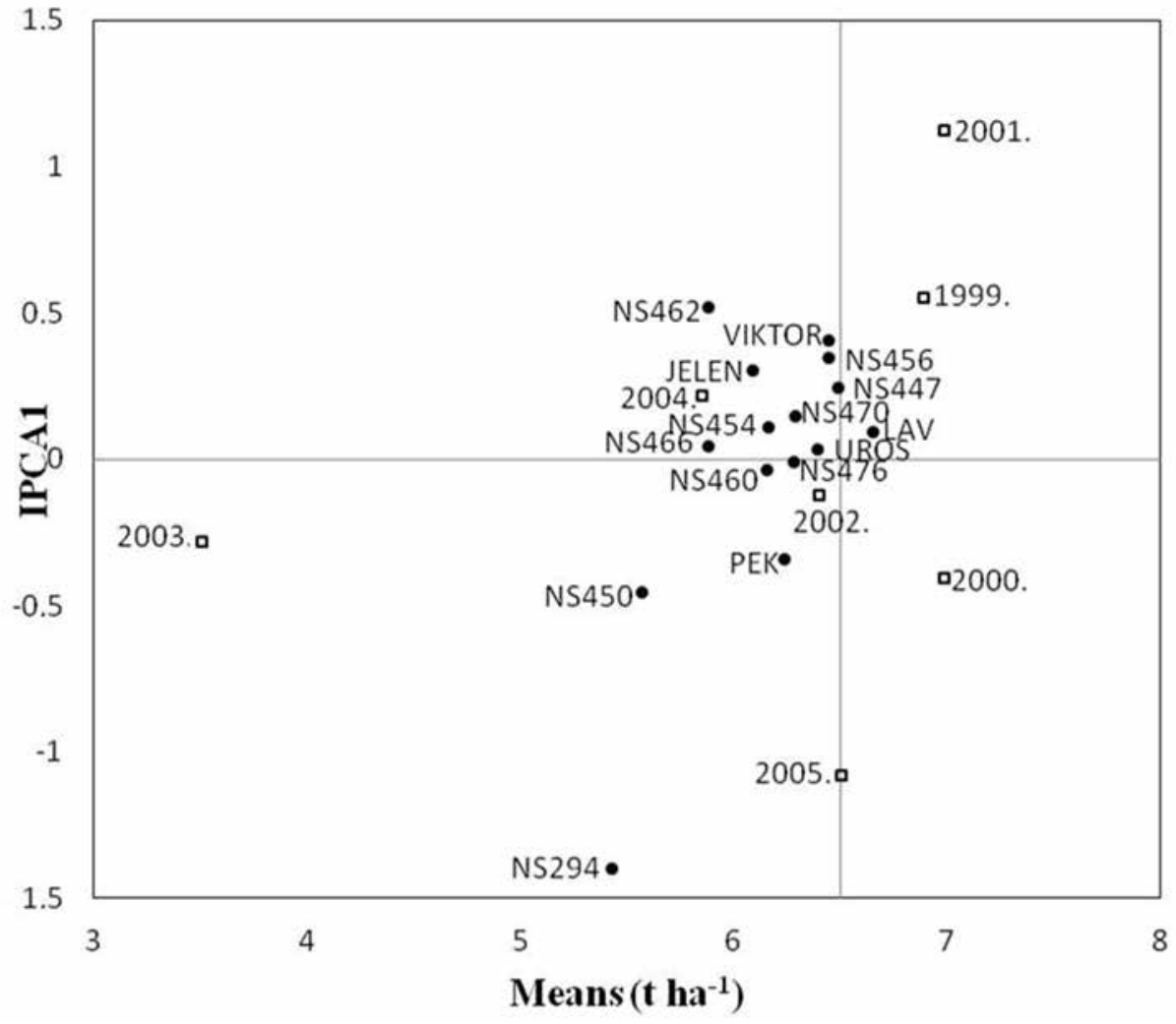

Figure 2. AMMI1 biplot of 15 barley varieties across seven years 
Among tested genotypes, NS 476, UROS, NS 466 and NS 460 were the most stable genotypes (Fig. 2). Genotype LAV had highest average yield, followed by NS 456, NS 447, Viktor and UROS. However, due to its better stability, LAV could be clearly separated for further breeding program and commercial farmer production. The years 2002 and 2004 were the largest contributors to stability of tested genotypes, since they had lowest IPCA1 values. On the other hand, years 2001 and 2005 gave the largest contribution to $\mathrm{G} \times \mathrm{Y}$ interaction. For example, in 2005 genotype NS 294 was the second highest yielding genotype, while in season 2001 had lowest yield. In contrast, NS462 was the lowest yielding in 2005, while in 2001 it was among three best yielding genotypes, just behind LAV and NS447 (Table 2).

AMMI2 biplot (Fig. 3) was generated using genotypic and environmental scores of the first two IPCA axes. Genotypes placed near biplot origin are more stable compared to genotypes positioned further away. Among the tested genotypes, UROS was placed closest to the origin and could be highlighted as the most stable genotype.

Genotypes and environments that were placed close to each other have positive association. For instance, genotypes NS454 and NS456 was placed near season 2004, and in

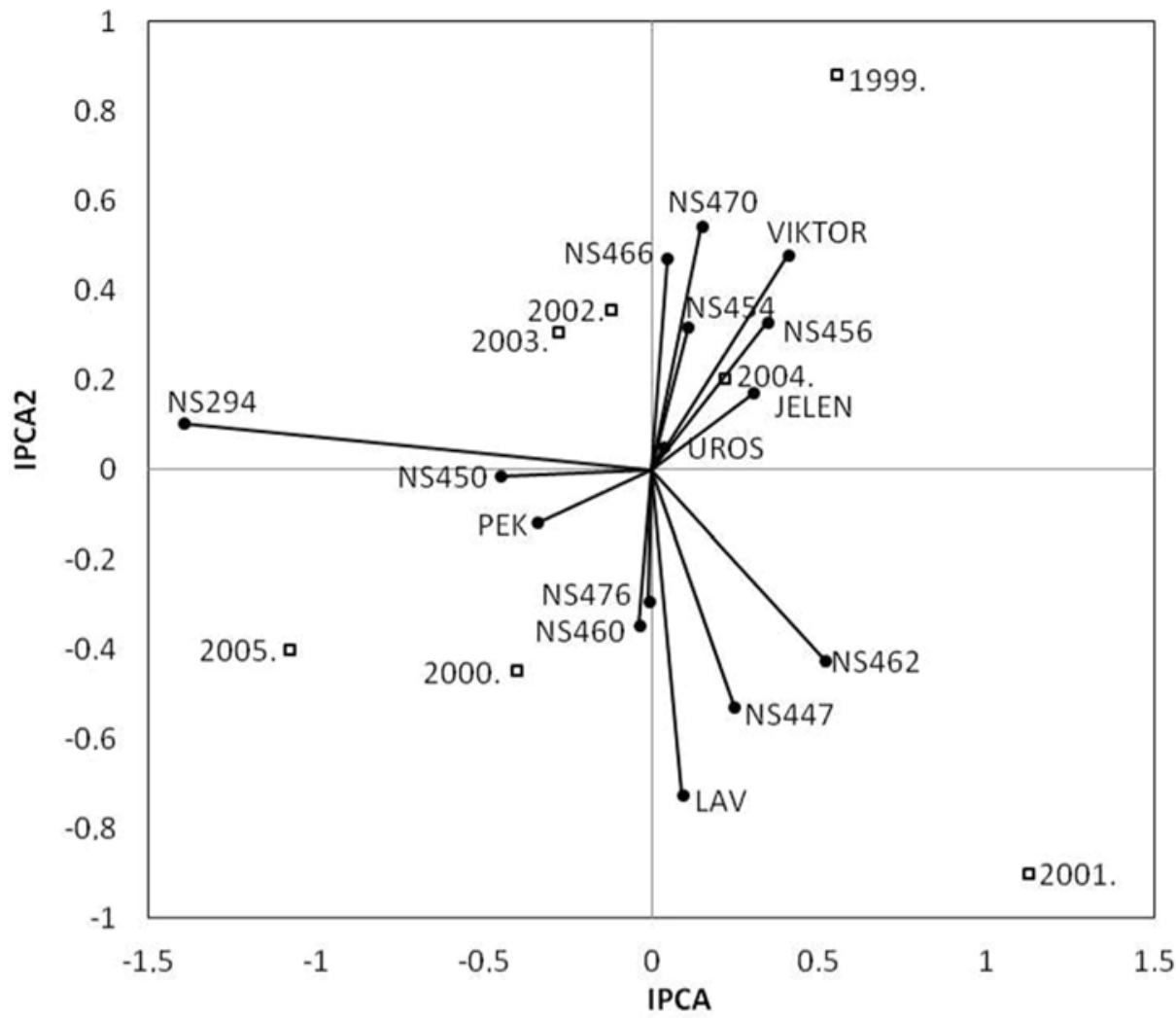

Figure 3. AMMI2 biplot of 15 barley varieties across seven years 
this season they were among best yielding genotypes, especially NS456 which was second yielding. Similarly, NS476 and NS460 were correlated with season 2000. NS470 had specific adaptation to season 1999, but reacted negatively with season 2000. NS447, NS462 and LAV were positively associated with season 2001, but negatively with season 2002.

\section{Discussion}

Standard statistical methods including ANOVA, PCA and linear regression are often used for yield trials analyses. According to Zobel et al. (1988), these traditional methods are often inadequate for appropriate understanding of complex data structure of yield trials. On the other hand, AMMI combines ANOVA and PCA into a single model with additive and multiplicative parameters and detects a highly significant interaction component that has clear agronomic meaning (Gauch and Zobel 1996). AMMI model is usually constructed from the first two IPCA axes, although some researchers recommended models with first three or four IPCA axes (Sivapalan et al. 2000). Kaya et al. (2002) stated that the most accurate model for AMMI can be predicted by using the first two IPCAs. In our study, the results of AMMI analysis revealed that the first IPCA was significant and captured $43.79 \%$ of $\mathrm{G} \times \mathrm{Y}$ interaction sum of squares in $22.62 \%$ of the interaction degrees of freedom and second IPCA explained additional $23.25 \%$ of interaction sum of squares. Moreover, Gauch and Zobel (1996) recorded that third and higher IPCA axes are dominated by noise and have no predictive value and clear biological interpretability. Our results also showed interaction of the 15 genotypes with seven environments was best predicted by the first two IPCAs, since they cumulatively explained $67 \%$ of $\mathrm{G} \times \mathrm{E}$ interaction.

The results from AMMI table (Table 2) further show that observed difference between tested Y had highest influence on barley grain yield and explain $80.97 \%$ of total treatment variation. In our study, effect of $G$ and $G \times Y$ interaction explained $6.79 \%$ and $12.25 \%$ of treatment variation, respectively. Romagosa and Fox (1993) also reported that effect of environment explained $80-90 \%$ of treatment variation in yield trials, and variation due to $\mathrm{G} \times \mathrm{E}$ interaction was usually higher than genotypic variation. Our results are in agreement with Yan and Rajcan (2002), who stated that E typically captured the highest percent of total treatment variation (up to $80 \%$ ), while the influence of $\mathrm{G}$ and $\mathrm{G} \times \mathrm{E}$ interaction is usually smaller.

High percentage of treatment variation explained by Y influence (Table 2) indicated that ecological conditions for barley growth considerably varied between the growing seasons. In order to provide better understanding of the differences between years in which the genotypes were tested and association between grain yield and climate conditions in three growth phases and growing seasons, biplot with meteorological variables, years and grain yield was constructed (Fig. 1). Yield components of barley are formed continually from the beginning of tillering to maturity and determined by developmental events that occur during plant phenological phases (Slafer 2003). During the vegetative (pre-anthesis) period spike number per unit area and kernel number per spike is estab- 
lished, i.e. the number of kernels per unit area is formed (Pržulj et al. 2014). On the other hand, kernel weight is formed during the period between anthesis and physiological maturity (Slafer 2003). Although many studies about grain yield have been focused on the grain filling period, the periods preceding anthesis and during anthesis seem to be equally important for grain yield establishment. Appearance of high temperature stress at anthesis reduced grain number per ear and harvest index (Ugarte et al. 2007). High temperature during the period that precedes anthesis reduces grain weight, as the consequence of negative temperature effects on carpel growth that occur in time of anthesis (Calderini et al. 2001).

Genotype and environmental conditions such as precipitation and temperature have strong influence on plant development. Negative influence of high temperature and water deficit on barley grain yield observed by other authors (Schelling et al. 2003) has also been found in our study. Season 2003 was characterized by the lowest average grain yield (Table 1) and highest minimum and maximum temperatures at emergence-heading and heading-maturity periods and the lowest sum of precipitation (Figure 1). Low yield of barley is often the result of grain filling period shortening, which is the consequence of high temperatures and/or insufficient water supply. Estimates for wheat indicate that for every $1{ }^{\circ} \mathrm{C}$ increase in temperature above $15^{\circ} \mathrm{C}$ there is a reduction of $3-4 \%$ in yield (Wardlaw et al. 1989). High temperature during pre-anthesis period in season 2003 decreased the final number of tillers (Pržulj and Momčilović 2012), which is in agreement with the results of Garcia del Moral et al. (2003). Besides negative effects on barley grain yield, high temperatures and drought stress increased protein concentration in barley grain (data not shown), which is in negative correlation with malt quality (Passarella et al. 2008). In contrast to year 2003, 2001 was characterized by high average grain yield and favourable climate for barley growth. Combination of moderate temperatures and adequate level of rainfall during tillering, spike development and grain filling, enabled the achievement of high yield. NS447, NS462 and LAV had high yield in 2001 and were positively associated with this season (Fig. 3), and therefore these three genotypes could be recommended for production in regions with increased level of rainfall.

Based on this study, it could be concluded that AMMI1 and AMMI2 models are very applicable for analysis of barley multi-year trials. Among the tested genotypes, LAV and NS 447 could be distinguished as highest yielding genotypes. Furthermore, due to higher stability, LAV could be recommended for further breeding program and large scale production in diverse climate conditions. Biplot revealed a strong negative association between grain yield and temperature variables recorded at emergence-heading and headingmaturity periods and that level of precipitation at heading-maturity period had higher association with grain yield than at other growing phases.

\section{Acknowledgements}

This paper presents the results of the project TR-31066 "Modern breeding of small grains for present and future needs", supported by the Ministry of Education, Science and Technological Development of the Republic of Serbia. 


\section{References}

Annicchiarico, P. 1997. Additive main effects and multiplicative interaction (AMMI) of genotype-location interaction in variety trials repeated over years. Theor. Appl. Genet. 94:1072-1077.

Calderini, D.F., Savin, R., Labeled, O.G., Reynolds, M.P., Slafer, G.A. 2001. The importance of the period immediately preceding anthesis for grain weight determination in wheat. Euphytica 119:199-204.

Ceccarelli, S. 1989. Wide adaptation. How wide? Euphytica 40:197-205.

Ceretta, S., van Eeuwijk, F. 2008. Grain yield variation in malting barley cultivars in Uruguay and its consequences for the design of a trials network. Crop Sci. 48:167-180.

FAOSTAT 2012. Food and Agriculture Organization (FAO): FAOSTAT. (Available at http://faostat.fao.org)

Garcia del Moral, L.F., Rharrabti, Y., Villegas, D., Royo, C. 2003. Evaluation of grain yield and its components in durum wheat under Mediterranean conditions: an ontogenic approach. Agron. J. 95:266-274.

Gauch, G.H., Zobel, R.W. 1996. AMMI analysis of yield trials. In: Kang, M.S., Gauch, H.G. (eds), Genotype by environment interaction. CRC Press. Boca Raton, FL, USA. pp. 85-122.

Kaya, Y., Palta, C., Taner, S. 2002. Additive main effects and multiplicative interactions analysis of yield performances in bread wheat genotypes across environments. Turk. J. Agric. For. 26:275-279.

Kilic, H., Sagir, A., Bayram, Y. 2009. Estimates of genotype x environment interactions and heritability of black point in durum wheat. Not. Sci. Biol. 1:92-96.

Lipkovich, I., Smith, E.P. 2002. Biplot and singular value decomposition macros for Excel. J. Stat. Softw. 7:1-15.

Metzger, M.J., Bunce, R.G.H., Jongman, R.H.G., Mücher, C.A., Watkins, J.W. 2005. A climatic stratification of Europe. Global Ecol. Biogeogr. 14:549-563.

Mitrović, B., Stanisavljević, D., Treskić, S., Stojaković, M., Ivanović, M., Bekavac, G., Rajković, M. 2012. Evaluation of experimental maize hybrids tested in multilocation trials using AMMI and GGE biplot analyses. Turk. J. Field Crops. 17:35-40.

Mladenov, V., Banjac, B., Krishna, A., Milošević, M. 2012. Relation of grain protein content and some agronomic traits in European cultivars of winter wheat. Cereal Res. Commun. 40:532-541.

Olesen, J.E., Trnka, M., Kersebaum, K.C., Skjelvag, A.O., Seguin, B., Peltonen-Sainio, P., Rossi, F., Kozyra, J., Micale, F. 2011. Impacts and adaptation of European crop production systems to climate change. Eur. J. Agron. 34:96-112.

Passarella, V.S., Savin, R., Slafer, G.A. 2008. Are temperature effects on weight and quality of barley grains modified by resource availability? Aust. J. Agric. Res. 59:510-516.

Pržulj, N., Momčilović, V. 2012. Spring barley performances in the Pannonian zone. Genetika 44:499-512.

Pržulj, N., Momčilović, V., Simić, J., Mirosavljević, M. 2014. Effect of growing season and variety on quality of spring two-rowed barley. Genetika 46:59-73.

Rao, P.S., Reddy, P.S., Rathore, A., Reddy, B.V., Panwar, S. 2011. Application GGE biplot and AMMI model to evaluate sweet sorghum (Sorghum bicolor) hybrids for genotype $\times$ environment interaction and seasonal adaptation. Ind. J. Agric. Sci. 81:438-844.

Romagosa, I., Fox, P. 1993. Genotype × environment interaction and adaptation. In: Hayward M.D., Bosemark, N.O., Romagosa, I. (eds), Plant Breeding: Principles and Prospects. Chapman and Hall. London, UK. pp. 373-390.

Romagosa, I., van Eeuwijk, F.A., Thomas, W.T.B. 2009. Statistical analyses of genotype by environment data. In: Phohens, J., Nuez, F., Carena, M.J., (eds), Handbook of Plant Breeding. Elsevier. New York, NY, USA. pp. $1-41$.

Schelling, K., Born, K., Weissteiner, C., Kühbauch, W. 2003. Relationships between yield and quality parameters of malting barley (Hordeum vulgare L.) and phenological and meteorological data. J. Agron. Crop Sci. 189:113-122.

Shah, N.H., Paulsen, G.M. 2003. Interaction of drought and high temperature on photosynthesis and grainfilling of wheat. Plant Soil 257:219-226.

Sivapalan, S., Brien, L.O., Ferrara, G.O., Hollamby, G.L., Barclay, I, Martin, P.J. 2000. An adaptation analysis of Australian and CIMMYT/ICARDA wheat germplasm in Australian production environments. Aust. J Agric. Res. 51:903-915. 
Slafer, G.A. 2003. Genetic basis of yield as viewed from a crop physiologist's perspective. Ann. Appl. Biol. 142:117-128.

StatSoft, Inc. 2011. STATISTICA (data analysis software system), version 10 (www.statsoft.com).

Ugarte, C., Calderini, D.F., Slafer, G.A. 2007. Grain weight and grain number responsiveness to pre-anthesis temperature in wheat, barley and triticale. Field. Crop. Res. 100:240-248.

Ullrich, S.E. 2011: Significance, adaptation, production, and, trade of barley. In: Ullrich, S.E., (ed.), Barley production, improvement, and uses. John Wiley \& Sons Inc. Ames, IA, USA. pp. 3-13.

Wardlaw, I.F., Dawson, I.A., Munibi, P., Fewster, R. 1989. The tolerance of wheat to high temperatures during reproductive growth. Survey procedures and general response patterns. Aust. J. Agric. Res. 40:1-13.

Yan, W., Rajcan, I. 2002. Biplot analysis of test sites and trait relations of soybean in Ontario. Crop Sci. 42:11-20.

Zobel, R., Wright, M.J., Gauch, H.G. 1988. Statistical analysis of yield trial. Agron. J. 80:388-393. 